\title{
Outcomes of paediatric patients ventilated in a high-care area outside an intensive care unit
}

\author{
S K Cawood, MB ChB, FC Paed (SA), MMed (Paed), Cert Critical Care (SA) Paed; S Naidoo, MB BCh, DCH (SA), FC Paed (SA), \\ Cert Nephrology (SA) Paed; G Okudo, MB ChB, FC Paed (SA), Cert Gastroenterology (SA); S Velaphi, MB ChB, FC Paed (SA), \\ MMed (Paed), PhD; C Verwey, MB ChB, MMed (Paed), FC Paed (SA), Cert Pulmonology (SA) Paed
}

Department of Paediatrics, Faculty of Health Sciences, University of the Witwatersrand, Johannesburg, South Africa

Corresponding author: S K Cawood (shancawood@gmail.com)

\begin{abstract}
Background. Limited availability of paediatric intensive care beds in the public sector is a major challenge in South Africa. It often results in patients being ventilated in a high-care area (HCA) outside an intensive care setting. The outcomes of paediatric patients ventilated outside a paediatric intensive care unit (ICU) are not well documented.

Objectives. To describe characteristics and outcomes of patients ventilated in a paediatric HCA.

Methods. A retrospective chart review of children (0 - 16 years) requiring mechanical ventilation in the HCA at Chris Hani Baragwanath Academic Hospital, Johannesburg, between 1 February and 31 October 2015 was performed.

Results. A total of 214 patients required mechanical ventilation during the study period. Fifty-four percent were male and $91.1 \%$ were HIV-negative. The most common diagnoses were acute lower respiratory tract infections $(59.3 \%$ of the post-neonatal group, $28.8 \%$ of the neonatal group) and sepsis ( $6.8 \%$ of the post-neonatal group, $28.8 \%$ of the neonatal group). The ultimate rate of acceptance to an ICU was $69.0 \%$. Only $41.6 \%$ of cases referred to an ICU were initially accepted, with limited bed availability being the main reason for refusal. Patients with respiratory illnesses were more likely and those with neurological illness less likely to be accepted to an ICU. Patients with low-risk diagnoses were more likely to be accepted than those with very high-risk diagnoses. The overall mortality rate was $32.2 \%$, with $52.2 \%$ of these deaths occurring in the HCA. Patients aged $1-5$ years had the highest mortality rate $(48.0 \%)$. Lower respiratory tract infections $(36.8 \%)$ and sepsis $(20.6 \%)$ were the main causes of death. The mortality rate of suitable ICU candidates in the HCA was higher than that in an ICU (33.3\% v. 24.3\%). The standardised mortality ratio (SMR), as predicted by the Paediatric Index of Mortality 3 score, for all patients who died in the HCA was 3.3, while the SMR for patients who died in an ICU was 1.3. The odds ratio for mortality of suitable candidates ventilated in the HCA v. patients who were ventilated in an ICU was 1.80 (95\% confidence interval $1.39-6.03)$.

Conclusions. Although a reasonable number of paediatric patients ventilated in an HCA survive, survival is lower than in those ventilated in an ICU. However, offering life-supporting therapies in an HCA may offer benefit where ICU care is unavailable. Emphasis needs to be placed on improving access to ICU care as well as optimising the use of available resources.
\end{abstract}

S Afr Med J 2020;110(9):903-909. https://doi.org/10.7196/SAMJ.2020.v110i9.14631

Intensive care has become an integral aspect of medical care, with ongoing development of medical strategies to treat medical conditions and prolong life. ${ }^{[1]}$ Studies have demonstrated that intensive care in low- and middle-income countries (LMICs) is not always equitable, with some children not having access to an intensive care unit (ICU) while others are kept alive at great cost when the chance of a good outcome is low. ${ }^{[2]}$ South Africa (SA), an LMIC, has a high burden of disease but limited availability of paediatric critical care beds. The high cost of trained healthcare workers and limited resources have limited development of our ICUs, preventing paediatric patients from having access to critical care when they need it. ${ }^{[3]}$ Many paediatric ICUs (PICUs) use scoring systems, such as the Paediatric Index of Mortality 3 (PIM3) score, to prognosticate mortality and identify patients admitted to the PICU who have an increased risk of poor outcome. ${ }^{[4,5]}$ However, no scores exist to analyse patients with regard to prioritising PICU admission in resource-limited settings. The limited number of PICU beds often results in paediatric patients who require mechanical ventilation being managed in a general paediatric ward rather than in a PICU, even though this practice has been shown to increase morbidity and mortality. ${ }^{[2,6]}$ At Chris Hani Baragwanath Academic Hospital (CHBAH) in Soweto, Johannesburg, temporary ventilation for paediatric patients can be offered in a paediatric high-care area (HCA) while awaiting an ICU bed. However, patients ventilated outside PICUs are often managed by nurses who are not trained in critical care and by general paediatricians who are not intensivists.

\section{Objectives}

No studies have assessed whether the practice of ventilating in an HCA outside a PICU rather than in a ward carries the same morbidity and mortality as management in a PICU. The objective of the present study was to describe the characteristics and outcomes of paediatric patients receiving mechanical ventilation in a paediatric HCA outside a PICU and to compare their mortality rates with those for patients who were ventilated in a PICU.

\section{Methods}

\section{Study setting}

The study was conducted at $\mathrm{CHBAH}$, a tertiary hospital that admits an average of 15 - 30 paediatric patients daily, with an average of 7000 paediatric admissions per year. ${ }^{[7]}$ The hospital conducts 22 000 births per year and caters for neonatal admissions from $\sim 8000$ births from the surrounding midwife-operated units. In total, the neonatal unit has $\sim 4000$ admissions per year. A small 
percentage of paediatric patients may require mechanical ventilation and intensive care services at some point during their admission. These patients are admitted to the HCA in the paediatric admissions ward at the discretion of the admitting paediatrician while a request is being made to the ICU for an intensive care bed. The paediatric department is supported by a PICU and a neonatal intensive care unit (NICU). The PICU has the capacity for 9 paediatric beds, which are managed by paediatric intensivists with a nurse-to-patient ratio of $1: 1$. The NICU has the capacity for 18 beds and is run by neonatologists, with a nurse-to-patient ratio of 1:2. While patients are awaiting an ICU bed, the HCA has capacity to ventilate 2 patients at a time and can accommodate up to 10 non-ventilated patients. One qualified nursing sister manages the unit, with 2 - 3 enrolled nurses assisting her. Paediatric patients requiring ICU admission outnumber the beds available, resulting in many patients being denied ICU admission. These patients are then ventilated in the HCA until clinical improvement occurs and the patient is extubated, an ICU bed becomes available and the patient is transferred, the decision is taken to withdraw intensive care support, or the patient dies. Such decisions are made at the discretion of the attending paediatrician. The protocol guiding the admission of ventilated patients in the HCA states that the period of ventilation should not exceed 48 - 72 hours. However, the limited number of ICU beds available, coupled with the ICU admission criteria, often result in patients being ventilated for longer than the stipulated 48 - 72 hours, or in some instances in more than 2 patients being ventilated in the HCA at a time. Principles guiding patient selection for PICU admission at CHBAH (unpublished) are based on allowing as many patients for whom demonstrable benefit is likely as possible to be admitted. Patients selected should be those for whom intensive care is necessary for a severe reversible disease process, with reasonable potential for the patient to return to an independent, functional state. Patients considered to be poor PICU candidates include those with end-stage organ failure, advanced neoplastic disease, neurological devastation, severe malnutrition, genetic syndromes and malformations, or congenital heart lesions not amenable to surgical correction. HIV per se is not an exclusion criterion, but HIV stage, associated illness and potential for recovery should be considered.

\section{Study design}

This retrospective chart review was carried out in the paediatric HCA at CHBAH from 1 February 2015 to 31 October 2015. Patients aged $<16$ years who required invasive mechanical ventilation were identified using the HCA database. Data collected included baseline characteristics and outcomes, including survival to discharge from the ICU, which was collected using the REDCap electronic data capture tool hosted at the University of the Witwatersrand. ${ }^{\left[{ }^{[8]}\right.}$ Baseline characteristics included age, gender, anthropometric indices, HIV status, admission diagnosis, and indication for ventilation and parameters required to calculate the PIM3 score. Outcomes data included assessment of ICU suitability as specified above, acceptance to the ICU, transfer to the ICU and in-hospital mortality.

When grouping patients according to indication for ventilation, an arterial oxygen partial pressure to fractional inspired oxygen $(\mathrm{P} / \mathrm{F})$ ratio $\leq 300$ was used to define type 1 respiratory failure. An arterial carbon dioxide partial pressure $\geq 60 \mathrm{mmHg}$ was used to define type 2 respiratory failure.

PIM3 data were used to compare weighted risk diagnoses of suitable v. unsuitable ICU candidates. The PIM3 score groups diagnoses into very high-risk, high-risk and low-risk diagnoses. Very high-risk diagnoses include cardiac arrest prior to ICU admission, severe combined immune deficiency, leukaemia or lymphoma, postbone marrow transplant, liver failure and necrotising enterocolitis. High-risk diagnoses include spontaneous cerebral haemorrhage, cardiomyopathy or myocarditis, hypoplastic left heart syndrome, neurodegenerative disorders and septic shock. Low-risk diagnoses include asthma, bronchiolitis, croup, obstructive sleep apnoea, diabetic ketoacidosis and seizures. ${ }^{[4]}$

PIM3 data were used to calculate standardised mortality ratios (SMRs) by dividing the number of observed deaths by the number of expected deaths as predicted by the PIM3 score. The SMR is used as a surrogate marker for the quality of ICU care, with a result of 1 being normal or expected. A ratio $>1$ indicates that the ICU is faring worse than expected in terms of mortality outcomes, and a ratio of $<1$ that it is faring better than expected. ${ }^{[4]}$

\section{Data analysis}

Descriptive statistics were used to report the data. Categorical variables were described using frequencies and percentages. Continuous variables were described using medians, interquartile ranges and ranges, as the data were not normally distributed. Calculations were performed using Statistica version 12 software (StatSoft, USA).

\section{Ethics approval}

Ethical clearance was obtained from the University of the Witwatersrand Human Research Ethics Committee (Medical) (ref. no. M150821).

\section{Results}

During the 9-month study period, 20821 patients were seen in the paediatric outpatient department, of whom 4718 (22.7\%) required admission to the general paediatric wards and 969 (20.5\% of admissions) were admitted to the HCA. A total of 214 (4.5\%) of all patients admitted required invasive mechanical ventilation.

\section{Characteristics of all patients ventilated in the paediatric HCA}

Gender distribution was fairly equal, with male patients accounting for 115 cases $(53.7 \%)$. The majority of patients $(n=195 ; 91.1 \%)$ were HIV-negative. The majority $(n=169 ; 79.0 \%)$ were aged $<1$ year, with the median (range) age being 2.4 months ( 1 day - 15.4 years). There were 52 neonates $(24.3 \%)$, of whom $14(26.9 \%)$ were preterm. The median (range) age of neonates at admission was 15 (1 - 28) days. The median (range) age of all other paediatric patients excluding neonates was 4 months ( 29 days - 15.6 years). Further characteristics of patients are outlined in Table 1. HIV status was confirmed with an age-appropriate serological test.

The most common diagnosis in the neonatal group ( $n=19$ patients; $36.5 \%)$ was sepsis. The most common diagnosis in the postneonatal group ( $n=96$ patients; $59.3 \%$ ) was lower respiratory tract infection (Table 2). While type 1 respiratory failure was the most common indication for invasive mechanical ventilation in the post-neonatal group ( $n=73$ patients; $45.1 \%$ ), neonates were most frequently ventilated for apnoeas, with 16 neonates $(30.7 \%)$ having this indication for ventilation (Table 3). Seventy-seven patients $(36.0 \%)$ overall required vasoactive support.

\section{ICU referral}

Among the 214 patients who required ventilation in the HCA, an ICU bed was not requested for 17 (7.9\%). Nine of these patients were deemed to be poor candidates for intensive care by the attending 
Table 1. Baseline characteristics of paediatric patients requiring invasive mechanical ventilation in a high-care area

\begin{tabular}{lll}
\hline & Neonatal age group $(\mathbf{N}=\mathbf{5 2})$ & Post-neonatal age group $(N=\mathbf{1 6 2})$ \\
\hline Gender, $n$ (\%) & $31(59.6)$ & $84(51.9)$ \\
Male & $21(40.4)$ & $78(48.1)$ \\
Female & & \\
Age (months), $n(\%)$ & $52(100)$ & 0 \\
$0-1$ & 0 & $117(72.2)$ \\
$>1-12$ & 0 & $24(14.8)$ \\
$>12-60$ & 0 & $21(13.0)$ \\
$>60$ & & $5.0(3.7-9.9)$ \\
Anthropometric indices, median (range) & $2.9(2.2-3.4)$ & $58.0(52.0-73.0)$ \\
Weight (kg) & $50.0(47.8-52.0)$ & $-1.9(-3.4--0.5)$ \\
Height (cm) & $-1.5(-3.4--0.8)$ & $-1.7(-2.9-0.4)$ \\
Weight for age $(z$-score) & $-1.0(-2.2-0.3)$ & $-0.9(-2.5-0.7)$ \\
Height for age $(z$-score) & $-2.0(-3.6--0.1)$ & \\
Weight for height $(z$-score) & & $143(88.3)$ \\
HIV status, $n$ (\%) & $52(100)$ & $93(65.0)$ \\
Negative & $27(51.9)$ & $50(35.0)$ \\
Unexposed, uninfected & $25(48.1)$ & $19(11.7)$ \\
Exposed, uninfected & 0 & $3(15.8)$ \\
Positive & 0 & $16(84.2)$ \\
Positive, on HAART & 0 & \\
Positive, not on HAART & & \\
HAART = highly active antiretroviral therapy. & &
\end{tabular}

\section{Table 2. Diagnoses of paediatric patients requiring invasive mechanical ventilation in a high-care area}

\begin{tabular}{|c|c|c|}
\hline Diagnosis & Neonatal age group $(N=52), n(\%)$ & Post-neonatal age group $(N=162), n(\%)$ \\
\hline Respiratory & $16(30.8)$ & $99(61.1)$ \\
\hline Lower respiratory tract infection & $15(93.8)$ & $96(97.0)$ \\
\hline Upper airway obstruction & $1(6.2)$ & $3(3.0)$ \\
\hline Cardiac & $1(1.9)$ & $11(6.8)$ \\
\hline Congenital heart disease & $1(100)$ & $4(36.4)$ \\
\hline Dilated cardiomyopathy/myocarditis & 0 & $7(63.6)$ \\
\hline Renal & 0 & $7(4.3)$ \\
\hline Nephrotic syndrome & 0 & $4(57.1)$ \\
\hline Chronic kidney disease & 0 & $3(42.9)$ \\
\hline Neurological & $5(9.6)$ & $14(8.6)$ \\
\hline Seizures & 0 & $7(50.0)$ \\
\hline Encephalopathy & 0 & $3(21.4)$ \\
\hline Acute flaccid paralysis & 0 & $1(7.2)$ \\
\hline Meningitis & $5(100)$ & $3(21.4)$ \\
\hline Endocrine & 0 & $1(0.7)$ \\
\hline Diabetic ketoacidosis & 0 & $1(100)$ \\
\hline Infectious & $25(48.1)$ & $15(9.3)$ \\
\hline Sepsis (including neonatal sepsis) & $19(76.0)$ & $11(73.3)$ \\
\hline Acute gastroenteritis & $6(24.0)$ & $4(26.7)$ \\
\hline Gastrointestinal/hepatic & $4(7.7)$ & $2(1.2)$ \\
\hline NEC & $2(50.0)$ & 0 \\
\hline Malrotation & 0 & $1(50.0)$ \\
\hline Intussusception & 0 & $1(50.0)$ \\
\hline Bilirubin encephalopathy & $2(50.0)$ & 0 \\
\hline Other & $1(1.9)$ & $13(8.0)$ \\
\hline Poisoning & 0 & $7(53.8)$ \\
\hline Malignancy & 0 & $5(38.5)$ \\
\hline Burns & $1(100)$ & 0 \\
\hline Near-drowning & 0 & $1(7.7)$ \\
\hline
\end{tabular}




\begin{tabular}{|c|c|c|}
\hline Indication for ventilation & Neonatal age group $(N=52), n(\%)$ & Post-neonatal age group $(N=162), n(\%)$ \\
\hline Respiratory & $38(73.1)$ & $122(75.3)$ \\
\hline Type 1 respiratory failure & $15(39.5)$ & $73(59.8)$ \\
\hline Type 2 respiratory failure & $7(18.4)$ & $27(22.1)$ \\
\hline Apnoeas & $16(42.1)$ & $18(14.8)$ \\
\hline Upper airway obstruction & 0 & $4(3.3)$ \\
\hline Circulatory & $14(26.9)$ & $23(14.2)$ \\
\hline Cardiorespiratory arrest & $3(21.4)$ & $7(30.4)$ \\
\hline Cardiac failure & 0 & $1(4.4)$ \\
\hline Shock, cardiogenic & 0 & $3(13.0)$ \\
\hline Shock, septic & $4(28.6)$ & $4(17.4)$ \\
\hline Shock, hypovolaemic & $1(7.1)$ & 0 \\
\hline Severe metabolic acidosis & $6(42.9)$ & $8(34.8)$ \\
\hline Neurological & 0 & $13(8.0)$ \\
\hline Airway protection & 0 & $13(100)$ \\
\hline Pre/post-surgery/intervention & 0 & $4(2.5)$ \\
\hline
\end{tabular}

paediatrician, 7 improved and were extubated soon after admission, and 1 died before an ICU bed could be requested. Of the 197 patients for whom consultation with the ICU took place, a total of $136(69.0 \%)$ were accepted to the ICU, $82(60.3 \%)$ on the day of consultation and the remainder at a point after the first day. Fig. 1 outlines the overall outcome of all 214 patients.

\section{Analysis of ICU suitability}

When an ICU bed is requested for a patient, that patient should be assessed regarding candidacy for admission to ICU. Of the 214 patients, 148 were assessed as being suitable candidates for ICU admission, notwithstanding bed status. Thirty-one patients were assessed as being poor or unsuitable candidates. Nine of these patients were deemed unsuitable ICU candidates by the attending paediatrician in the HCA and were among the 17 cases in which the ICU was not consulted. In 22 cases in which the ICU was consulted, the patient was initially refused an ICU bed on the grounds of being an unsuitable candidate (however, 4 of these patients were later reassessed with subsequent improvement and accepted to an ICU). The remaining 35 of the 214 patients were refused ICU admission owing to lack of bed availability with no assessment of ICU candidacy being made. An analysis was carried out to determine whether characteristics differed between the 148 patients assessed as being suitable candidates for ICU admission and the total of 31 patients initially assessed as being unsuitable candidates. The 35 patients for whom assessment of candidacy was not made were excluded from this analysis (Table 4).

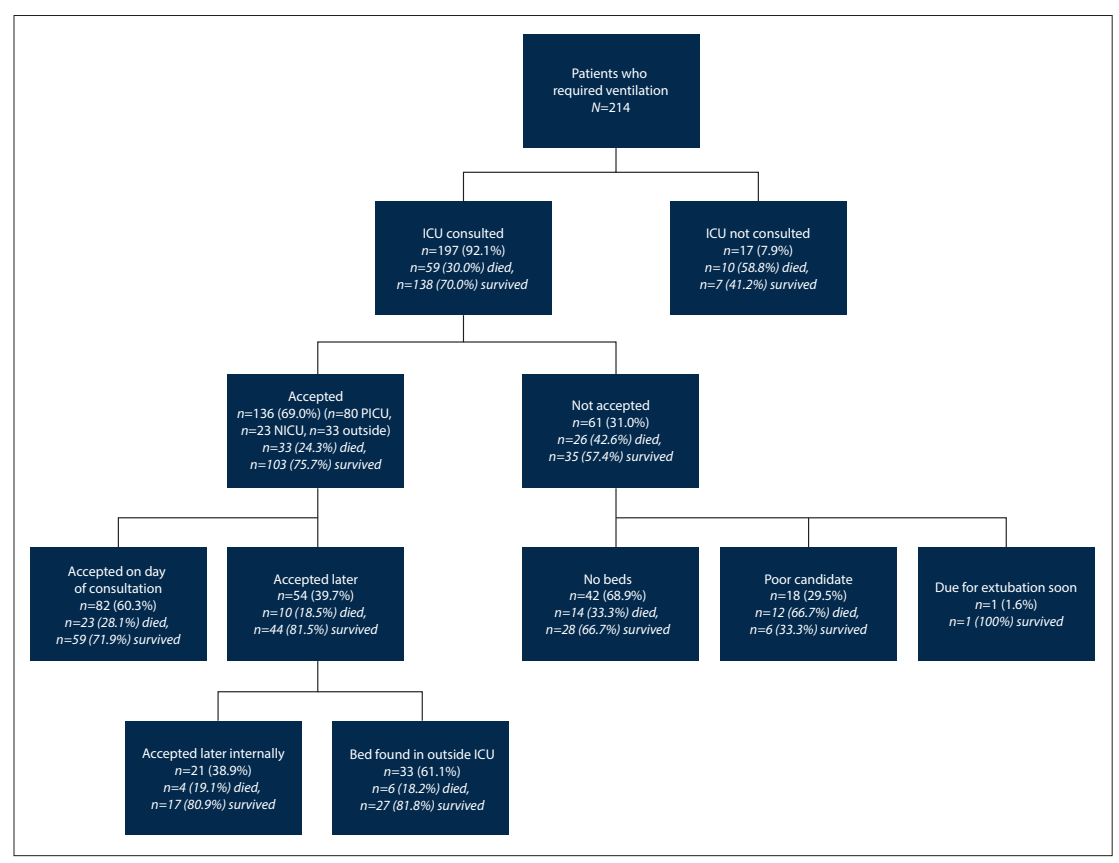

Fig. 1. ICU acceptance and mortality outcomes of patients ventilated in an HCA. (ICU = intensive care unit; $H C A=$ high-care area.)

\section{Mortality and mortality scores}

Of the 214 patients, 69 (32.2\%) died. The age group $1-5$ years had the highest mortality rate $(48.0 \%)$, and neonates the next highest (38.5\%). The main diagnosis in patients who died was lower respiratory tract infection (36.8\%), followed by sepsis (20.6\%).

Sufficient data to calculate PIM3 scores were available for 32 of the 69 patients overall who died and for 111 of the 145 overall who survived. This comparison is illustrated in Table 5. Factors contributing to an increased risk of mortality included need for vasoactive support and high-risk diagnoses, both of which contribute to a worse PIM3 score. An overall SMR was calculated at 2.2 for those cases in which enough data were available to calculate a PIM3 score.

Comparison between PIM3 scores of the 148 patients deemed suitable ICU candidates v. the 31 patients deemed unsuitable was not done, as there were insufficient data to calculate PIM3 scores in enough patients to make the comparison accurate.

An analysis of PIM3 scores and probability of mortality scores in the 33 patients who died in the ICU compared with the 36 patients who died in the HCA was done (Table 6). The SMR for patients who died in the ICU was 1.3, while that for patients who died in the HCA was 3.3. 


\begin{tabular}{|c|c|c|c|}
\hline & Suitable candidate $(N=148)$ & Unsuitable candidate $(N=31)$ & $p$-value \\
\hline \multicolumn{4}{|l|}{ Continuous variables, median (range) } \\
\hline Age (months) & $2.7(1.0-6.6)$ & $6.3(0.9-38.8)$ & 0.55 \\
\hline Weight for age ( $z$-score) & $-1.6(-3.4--0.5)$ & $-2.2(-3.6--0.8)$ & 0.39 \\
\hline Height for age ( $z$-score) & $\begin{array}{l}-1.5(-3.6--0.3) \\
\left(N=105^{\star}\right)\end{array}$ & $\begin{array}{l}-1.7(-2.6--1.3) \\
\left(N=15^{\star}\right)\end{array}$ & 0.45 \\
\hline Weight for height ( $z$-score) & $\begin{array}{l}-0.5(-2.5-1.0) \\
\left(N=103^{\star}\right)\end{array}$ & $\begin{array}{l}-2.0(-3.0--0.7) \\
\left(N=15^{*}\right)\end{array}$ & 0.08 \\
\hline \multicolumn{4}{|l|}{ Categorical variables, $n(\%)$} \\
\hline HIV status & & & 0.47 \\
\hline Positive & $14(9.5)$ & $2(6.5)$ & \\
\hline Negative & $134(90.5)$ & $29(93.5)$ & \\
\hline \multicolumn{4}{|l|}{ Diagnosis } \\
\hline Respiratory & $100(67.5)$ & $4(12.9)$ & 0.78 \\
\hline Cardiac & $6(4.1)$ & $5(16.1)$ & 0.50 \\
\hline Renal & $6(4.1)$ & $1(3.2)$ & 0.64 \\
\hline Neurological & $8(5.4)$ & $7(22.6)$ & 0.60 \\
\hline Endocrine & $1(0.7)$ & 0 & 0.99 \\
\hline Infectious & $17(11.4)$ & $9(29.0)$ & 0.44 \\
\hline Neonatal & $4(2.7)$ & $2(6.5)$ & 0.85 \\
\hline Other & $6(4.1)$ & $3(9.7)$ & 0.68 \\
\hline \multicolumn{4}{|c|}{ Weighted diagnosis according to PIM3 score } \\
\hline Very high risk & $3(2.0)$ & $10(32.3)$ & 0.34 \\
\hline High risk & $24(16.2)$ & $11(35.4)$ & 0.57 \\
\hline Low risk & $121(81.8)$ & $10(32.3)$ & 0.52 \\
\hline \multicolumn{4}{|l|}{ Mechanical ventilation } \\
\hline Respiratory & $128(86.5)$ & $11(35.4)$ & 0.87 \\
\hline Cardiac & $12(8.1)$ & $16(51.7)$ & 0.93 \\
\hline Neurological & $6(4.1)$ & $4(12.9)$ & 0.83 \\
\hline Pre/post-surgery/intervention & $2(1.43)$ & 0 & 0.99 \\
\hline \multicolumn{4}{|l|}{ Need for vasoactive support } \\
\hline Yes & $38(25.7)$ & $20(64.5)$ & 0.93 \\
\hline No & $110(74.3)$ & $11(35.5)$ & 0.40 \\
\hline
\end{tabular}

\section{Table 5. PIM3 scores and probability of mortality scores in patients who died v. those who survived}

\begin{tabular}{|c|c|c|c|}
\hline & $\operatorname{Died}\left(N=32^{\star}\right)$ & Survived $\left(N=111^{*}\right)$ & $p$-value \\
\hline PIM3 score, median (IQR) & $-3.9(-5.5--1.1)$ & $-5.1(-5.8--4.2$ & 0.01 \\
\hline Probability of mortality (\%), median (IQR) & $2.0(0.4-24.7)$ & $0.6(0.3-1.4)$ & 0.09 \\
\hline
\end{tabular}

Table 6. PIM3 scores and probability of mortality scores in patients who died in the ICU compared with patients who died in the HCA

\begin{tabular}{lccc}
\hline & Died in ICU $\left(\boldsymbol{N = 2 \mathbf { 1 } ^ { * } )}\right.$ & Died in HCA $\left(\boldsymbol{N}=\mathbf{3 6} \mathbf{6}^{*}\right)$ & $\boldsymbol{p}$-value \\
\hline PIM3 score, median (IQR) & $-5.1(-5.6--2.4)$ & $-2.0(-4.7--0.8)$ & 0.12 \\
Probability of mortality (\%), median (IQR) & $0.6(0.4-8.2)$ & $14.5(1.1-31.0)$ & 0.20
\end{tabular}

PIM3 = Paediatric Index of Mortality 3; ICU = intensive care unit; $\mathrm{HCA}=$ high-care area; IQR = interquartile range.
${ }^{*}$ Numbers in brackets represent the number of patients for whom data were available to calculate a PIM3 score.

When comparing patients who were deemed to be good candidates and were ventilated in the HCA with those who were ventilated in an ICU, whether internal or external, the unadjusted odds ratio (OR) of mortality was 1.8 (95\% confidence interval (CI) $1.4-6.0)$, indicating that mortality was increased in patients who were ventilated in the HCA v. patients who were ventilated in an ICU.

\section{Discussion}

In SA, a low-income environment, a high burden of disease paired with limited critical care bed availability and limited resources can prevent paediatric patients from having access to critical care if they need it. ${ }^{[3]}$ The limited PICU bed availability often results in paediatric patients who require mechanical ventilation being managed outside 
a PICU, even though this practice has been shown to increase morbidity and mortality ${ }^{[2]}$ No studies have assessed whether the practice of ventilating in an HCA outside a PICU rather than in a ward carries the same morbidity and mortality as management in a PICU. This study represented an attempt to describe the characteristics and outcomes of paediatric patients receiving mechanical ventilation in a paediatric HCA outside a PICU and to compare their mortality rates with those for patients who were ventilated in a PICU.

The high burden of disease in SA was evident in this study, with $4.5 \%$ of all patients admitted to the paediatric service requiring intensive care. This figure is in keeping with other reported SA public hospital statistics of $\sim 7 \%$ of patients requiring intensive care services. ${ }^{[9]}$ The majority (69.0\%) of the patients referred to an ICU were ultimately accepted to an ICU, either internal or external. While limited literature regarding admission rates to ICUs in SA public hospitals is available, this figure is in keeping with reported admission rates of $65 \%$ and $72 \%$, although these figures are derived from audits of adult admissions. ${ }^{[10,11]}$ The most frequent reason for patients being denied ICU admission on the day of consultation was limited availability of ICU beds, as has been reported in other audits nationwide. ${ }^{[2,10,12]}$ Limited available current evidence reports that SA has critical care resource shortages in terms of both numbers of beds and trained staff, resulting in limitations in the number of ICU beds available..$^{[3,13,14]}$ Contributing to this problem is the discrepancy between the availability of resources in the public and private healthcare systems, with only $30 \%$ of doctors working in the public sector, which serves $>80 \%$ of the country's population. ${ }^{[13]}$ An audit of critical care resources carried out in 2004/05 showed that $84 \%$ of private hospitals but only $23 \%$ of public hospitals have ICUs or HCAs ${ }^{[3]}$ ICU beds should comprise 5 - 12\% of hospital beds. ${ }^{[3]}$ Private hospitals reach this target at $8.9 \%$, but public hospitals fall far short at $1.7 \% \cdot{ }^{[3]}$ In addition, the audit reported insufficient numbers of ICUtrained nurses, with the ratio of full-time nurses per functional bed reported at 1.1:1, with only $25.6 \%$ of these nurses being ICU trained. These figures are far below international guidelines, which recommend a ratio in excess of $5: 1$, with a minimum of $50 \%$ of nurses being ICU trained. ${ }^{[3]}$

This imbalance between demand and availability of resources in the public sector has resulted in the need for triaging of patients to prioritise ICU admission for patients who need intensive care the most. ${ }^{[14]}$ International guidelines for ICU admissions in developed countries with more resources have fewer exclusionary criteria and are difficult to apply in our resource-limited setting. ${ }^{[15]}$ A consensus statement to provide a framework to inform ICU admission, rationing and triage decision in an SA context was published recently. ${ }^{[14]}$ Furthermore, each ICU should develop its own specific admission criteria. ${ }^{[14]}$ In the present study, when determining the suitability of a patient for ICU admission, many patient characteristics were assessed with no significant difference in any characteristics, including HIV status, being found. Median anthropometric parameters were all within normal values, although there were some patients who fell outside the lower range of the normal $-2 z$-score for weight for age and height for age. While these patients were not individually assessed, perhaps this finding requires intensivists to scrutinise their selection of suitable candidates, which may be affecting outcomes. While there was little difference in weight alone between suitable and unsuitable candidates for intensive care, patients who were deemed unsuitable candidates had lower weight-for-height scores (i.e. were wasted); however, this difference was not found to be statistically significant. Studies have shown that although both HIV and malnutrition may result in increased length of mechanical ventilation and ICU stay, with resultant heavier burdens on PICUs, with the additional advent of highly active antiretroviral therapy, patients with HIV and malnutrition have improved short- and long-term outcomes and should not be denied access to intensive care ${ }^{[2,16-19]}$ However, it may be argued that our resource-limited setting perhaps requires us to be more discriminatory towards these patients in order to allow the limited resources to be used for patients with greater potential for benefit and longer functional outcome. In terms of patient diagnoses, patients with respiratory illnesses were more likely to be considered suitable ICU candidates and those with neurological illnesses were more likely to be considered poor candidates, although these findings were not statistically significant. This may tie in with the finding that patients with low-risk diagnoses, which include respiratory illnesses, were considered more suitable candidates and were more likely to be accepted to an ICU. Patients with very high-risk diagnoses and high-risk diagnoses, which include neurological disorders, were more likely to be deemed to be unsuitable candidates. Once again, these findings were not statistically significant. These results show that very high-risk patients in whom prognosis is uncertain are not getting the benefit of ICU care and may be deemed 'too ill' for ICU admission. This is consistent with literature suggesting that patients who are perceived to be too ill to benefit from critical care are more often refused admission to ICU when bed availability is limited. ${ }^{[20]}$

Where ICU resources are not available to a patient requiring critical care, hospitals and doctors should provide alternative solutions to provide the best possible care by appropriately trained staff in other settings. ${ }^{[14]}$ Because of scarce critical care resources, many SA hospitals provide life-supporting therapies such as mechanical ventilation in HCAs or general wards. ${ }^{[14]}$ While this may be appropriate for patients requiring lower levels of care, it worsens outcomes in those who require high levels of intensive care. ${ }^{[14]}$ In this study, the in-HCA mortality rate was higher than the in-ICU mortality rate $(46.2 \%$ v. $24.3 \%)$. However, this result is biased in that it compares patients admitted to an ICU who were deemed suitable candidates with all patients left in the HCA, who included both suitable and unsuitable ICU candidates. When comparing the in-ICU mortality rate with the in-HCA mortality rate of those who were deemed good ICU candidates but were denied admission owing to lack of availability of beds, the in-HCA mortality rate was closer to that for the ICU $(33.3 \%$ v. $24.3 \%)$. The overall mortality rate of $24.3 \%$ in an ICU, whether internal or external, is much higher than rates in developed countries. Studies report rates of between $2 \%$ and $7.5 \%$ for developed countries, ${ }^{[21-24]}$ while figures from developing countries are much more variable, with reported mortality rates between $8.8 \%$ and $36.1 \% \cdot{ }^{[2,25-28]}$ In the present study, the SMR, using predicted mortality based on the PIM3 score, for all patients who died in an HCA was 3.3, while the SMR for those patients who died in an ICU was 1.3 , indicating that more deaths occurred than predicted by the PIM3 score. Few studies report on PIM3 scores and SMRs, but in those that can be found, SMRs in ICUs vary greatly. A study in the $\mathrm{UK}^{[5]}$ reported SMRs between 0.6 and 0.9 , while a study in Turkey ${ }^{[29]}$ reported SMRs between 3.7 and 4.0. The higher than expected mortality in the present study may be attributed to a high burden of severe illness being managed in an under-resourced environment (both physical and human), resulting in differences in quality of care. However, available scores have demonstrated relatively poor performance in estimating mortality. ${ }^{[20]}$ While many scores, such as the PIM3, show reasonable discrimination, calibration is relatively poor, limiting their ability to predict outcome. ${ }^{[20]}$

The unadjusted OR of mortality between suitable ICU candidates who were ventilated in the HCA owing to unavailability of beds $v$. 
patients who were ventilated in an ICU was 1.80 (95\% CI 1.39 - 6.03), evidence that managing these patients outside an ICU increases their risk of mortality. This is in keeping with findings of a systematic review that patients who are referred to an ICU and refused had excess mortality even when adjusted for severity of illness, with a combined OR of death of up to 3 times that for patients who were accepted into an ICU. ${ }^{[20]}$ However, if an ICU is not available for these patients, offering life-supporting therapies in a ward or HCA may at least offer a benefit, even though not optimal. ${ }^{[14]}$ The recently published Critical Care Society of Southern Africa Consensus Statement on ICU Triage and Rationing ${ }^{[14]}$ recommended that 'Lower levels of care can be justified in certain circumstances' and that 'Where lower levels of care are offered as a substitute for ICU care, efforts to improve access for patients to ICU care should not be relaxed.'

To the best of our knowledge, this is the first SA study to describe the experience of ventilating paediatric patients outside an ICU in an HCA. It has relevance in light of the recently published Critical Care Society of Southern Africa Consensus Statement on ICU Triage and Rationing. ${ }^{[14]}$

\section{Study limitations}

Limitations of this study include limited numbers for analysis for ICU suitability where assessments on patient suitability were not carried out. Numbers for PIM3 score analysis were also limited where insufficient data were recorded to determine a PIM3 score, as is a limitation of retrospective study designs. Sample bias occurred where comparisons were made between outcomes of ICU patients against HCA patients, who included those who may not have been suitable ICU candidates.

\section{Conclusions}

Limited available current evidence shows that SA, an LMIC, has critical care resource shortages in terms of both bed numbers and trained staff, despite having a high burden of disease. This lack results in life-supporting therapies such as mechanical ventilation being provided in HCAs or general wards. The present study has shown that mortality is increased when paediatric patients are ventilated in an HCA rather than an ICU.

However, if intensive care is not available for these patients, offering life-supporting therapies in an HCA may offer some benefit and may be justified. While there is a need to increase access to ICU services, increasing ICU capacity may not be feasible immediately, and emphasis therefore needs to be placed on the optimal use of resources available. Measures should include clear ICU triage guidelines and admission criteria; effective, practical and equitable use of scarce resources; effective transport systems, both to the hospital and to the ICU; effective use of intensivists and other well-trained health professionals; and use of intermediate facilities such as the HCA for patients with lower critical care needs, with more intensive training of nursing and medical staff in charge of their care. ${ }^{[2,14,20,26,30-34]}$

Declaration. The research for this study was done in partial fulfilment of the requirements for SKC's MMed (Paed) degree at the University of the Witwatersrand.

Acknowledgements. None.

Author contributions. All authors contributed to the manuscript significantly and reviewed and agreed upon the manuscript content.

Funding. None.

Conflicts of interest. None.
1. Frey B. Overtreatment in threshold and developed countries. Arch Dis Child 2008;93(3):260-263. https://doi.org/10.1136/adc.2007.124479e

2. Argent AC, Ahrens J, Morrow BM, et al. Pediatric intensive care in South Africa: An account of

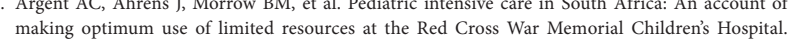
making optimum use of limited resources at the Red Cross War Memorial Childres'
Pediatr Crit Care Med 2014;15(1):7-14. https://doi.org/10.1097/pcc.0000000000000029

3. Bhagwanjee S, Scribante J. National audit of critical care resources in South Africa - unit and bed distributions. S Afr Med J 2007;97(12):1311-1314.

4. Straney L, Clements A, Parslow RC, et al. Paediatric index of mortality 3: An updated model for predicting mortality in pediatric intensive care. Pediatr Crit Care Med 2013;14(7):673-681. https:// doi.org/10.1097/pcc.0b013e31829760cf

5. Tibby SM, Taylor D, Festa M, et al. A comparison of three scoring systems for mortality risk among retrieved intensive care patients. Arch Dis Child 2002;87(5):421-425. https://doi.org/10.1136/ adc.87.5.421

6. Odetola FO, Rosenberg AL, Davis MM, et al. Do outcomes vary according to the source of admission to the pediatric intensive care unit? Pediatr Crit Care Med 2008;9(1):20-25. https://doi admission to the pediatric intensive care
org/10.1097/01.pcc.0000298642.11872.29

7. Chris Hani Baragwanath Hospital. Chris Hani Baragwanath Hospital, the biggest hospital in South Africa. 31 May 2015. http://www.chrishanibaragwanathhospital.co.za/ (accessed 18 February 2015). 8. Harris PA, Taylor R, Thielke R, et al. Research electronic data capture (REDCap) - a metadatadriven methodology and workflow process for providing translational research informatics support. J Biomed Inform 2009;42(2):377-381. https://doi.org/10.1016/j.jbi.2008.08.010

9. Westwood A, Levin M, Hageman J. Paediatric admissions to hospitals in the Cape Town Metro district: A survey. S Afr J Child Health 2012;6(2):31-37.

10. Hurri H. Profile of ICU bed requests at Helen Joseph Hospital. MMed thesis. Johannesburg: University of the Witwatersrand, 2015.

11. Gordon K, Allorto N, Wise R. Analysis of referrals and triage patterns in a South African metropolitan adult intensive care service. S Afr Med J 2015;105(6):491-495. https://doi.org/10.7196/ metropolita
SAMJ.9007

12. Burch VC, Benatar SR. Rational planning for health care based on observed needs. S Afr Med J 2006;96(9):796-802.

13. World Health Organization. Bridging the gap in South Africa. Bull World Health Organ 2010;88(11):797-876. http://www.who.int/bulletin/volumes/88/11/10-021110/en/ (accessed 18 February 2015).

14. Joynt G, Gopalan PD, Argent A, et al. The Critical Care Society of Southern Africa Consensus Statement on ICU Triage and Rationing (ConICTri). S Afr Med J 2019;109(8):613-629. https://doi. org/10.7196/SAMJ.2019.v109i8b.13947

15. Siddiqui NU, Ashraf $\mathrm{Z}$, Jurair $\mathrm{H}$, et al. Mortality patterns among critically ill children in a pediatric intensive care unit of a developing country. Indian J Crit Care Med 2015;19(3):147-150. https://doi. org/10.4103/0972-5229.152756

16. De Souza Menezes F, Leite HP, Koch Nogueira PC. Malnutrition as an independent predictor of De Souza Menezes F, Leite HP, Koch Nogueira PC. Malnutrition as an independent predictor of
clinical outcome in critically ill children. Nutrition 2012;28(3):267-270. https://doi.org/10.1016/j. clinical outcome

17. Argent AC. Managing HIV in the PICU - the experience at the Red Cross War Memorial Children's Hospital in Cape Town. Indian J Pediatr 2008;75(6):615-620. https://doi.org/10.1007/s12098-008$0118-2$

18. Cowburn C, Hatherill M, Eley B, et al. Short-term mortality and implementation of antiretroviral treatment for critically ill HIV-infected children in a developing country. Arch Dis Child 2007;92(3):234-241. https://doi.org/10.1136/adc.2005.074856

19. Rabie H, de Boer A, van den Bos S, et al. Children with human immunodeficiency virus infection admitted to a paediatric intensive care unit in South Africa. J Trop Pediatr 2007;53(4):270-273. https://doi.org/10.1093/tropej/fmm088

20. Sinuff T, Kahnamoui K, Cook DJ, et al. Rationing critical care beds: A systematic review. Crit Care Med 2004;32(7):1588-1597. https://doi.org/10.1097/01.ccm.0000130175.38521.9f

21. McHugh GJ, Hicks PR. Paediatric admissions to the general intensive care unit at Palmerston North McHugh GJ, Hicks PR. Paediatric admissions to the general intensive care unit at Palmersto
Hospital. Crit Care Resusc 1999;1(3):234-238. https://doi.org/10.1007/s00134-002-1227-4

22. Gemke RJ, Bonsel GJ. Comparative assessment of pediatric intensive care: A national multicenter study. Crit Care Med 1995;23(2):238-245. https://doi.org/10.1097/00003246-199502000-00007

23. Pollack MM, Holubkov R, Funai T, et al. Pediatric intensive care outcomes: Development of new morbidities during pediatric critical care. Pediatr Crit Care Med 2014;15(9):821-827. https://doi. org $/ 10.1097 /$ pcc. 0000000000000250

24. Prince NJ, Brown KL, Mebrahtu TF, et al. Weight-for-age distribution and case-mix adjusted outcomes of 14,307 paediatric intensive care admissions. Intensive Care Med 2014;40(8):1132-1139. https://doi.org/10.1007/s00134-014-3381-x

25. Jeena PM, Wesley AG, Coovadia HM. Admission patterns and outcomes in a paediatric intensive care unit in South Africa over a 25 -year period (1971 - 1995). Intensive Care Med 1999;25(1):88-94. care unit in South Africa over a 25-year
https://doi.org/10.1007/s001340050792

26. Embu HY, Yiltok SJ, Isamade ES, et al. Paediatric admissions and outcome in a general intensive care unit. Afr J Paediatr Surg 2011;8(1):57-61. https://doi.org/10.4103/0189-6725.78670

27. Bekhit Oel S, Algameel AA, Eldash HH. Application of Pediatric Index of Mortality version 2: Score in pediatric intensive care unit in an African developing country. Pan Afr Med J 2014;11(17):185 https://doi.org/10.11604/pamj.2014.17.185.2818

28. Haque A, Siddiqui NR, Jafri SK, et al. Clinical profiles and outcomes of children admitted to the pediatric intensive care unit from the emergency department. J Coll Physicians Surg Pak 2015;25(4):301-303. https://ecommons.aku.edu/pakistan_fhs_mc_women_childhealth_paediatr/203 (accessed 8 August 2020).

29. Ozer EA, Kizilgunesler A, Sarioglu B, et al. The comparison of PRISM and PIM scoring systems for mortality risk in infantile intensive care. J Trop Pediatr 2004;50(6):334-338. https://doi.org/10.1093/ tropej/50.6.334

30. Ballot DE, Davies VA, Rothberg AD, et al. Selection of paediatric patients for intensive care. S Afr Med J 1995;85(11):1221-1223, 1226.

31. Murthy S, Leligdowicz A, Adhikari NK. Intensive care unit capacity in low-income countries: A systematic review. PLoS ONE 2015;10(1):e0116949. https://doi.org/10.1371/journal.pone.0116949 32. Safar P, Grenvik A. Critical care medicine: Organizing and staffing intensive care units. Ches 1971;59(5):535-547. https://doi.org/10.1378/chest.59.5.535

33. Mayosi BM, Benatar SR. Health and health care in South Africa - 20 years after Mandela. $\mathrm{N}$ Engl Med 2014;371(14):1344-1353. https://doi.org/10.1056/nejmsr1405012

34. Wightman A, Largent E, del Beccaro M, et al. Who should get the last PICU bed? Pediatrics 2014;133(5):907-912. https://doi.org/10.1542/peds.2013-3369 